\title{
REFLEXIÓN SOBRE LA EVALUACIÓN EN LA FORMACIÓN INICIAL DEL PROFESORADO EN ESPAÑA. EN BÚSQUEDA DE LA CONCORDANCIA ENTRE DOS MUNDOS (1)
}

Reflection on the assessment in the initial training of teachers in spain. in search of the concordance between two worlds

Reflexão sobre avaliação na formação inicial de professores em espanha. em busca do acordo entre dois mundos

(1) Este estudio se ha llevado a cabo dentro del proyecto de I+D+I: "La competencias docentes en la formación inicial del profesorado de educación física". Convocatoria de noviembre de 2013 del Programa Estatal de Investigación, Desarrollo e Innovación Orientada a los Retos de la Sociedad, en el marco del Plan Estatal de Investigación Científica y Técnica y de Innovación 2013-2016. Referencia: EDU 2013-42024-R. Duración: 3 años (2014-2016).

Ángel Pérez Pueyo. Universidad de León, España. Fono: 987293024 angel.perez.pueyo@unileon.es

David Hortigüela Alcalá. Universidad de Burgos, España. Fono: 947259517 dhortiguela@ubu.es

Carlos Gutiérrez García. Universidad de León, España. Fono: 987293058 cgutg@unileon.es

\section{Resumen}

El presente artículo analiza y busca solución a la falta de concordancia entre la terminología de evaluación utilizada en el contexto universitario y la empleada en el ámbito no universitario. Tras analizar la trayectoria de la terminología de evaluación en el contexto educativo desde 1990 y comprobar que los términos de evaluación empleados por los autores que son referente en el ámbito universitario, nada tienen que ver con terminología educativa, se desvela la incoherencia de la formación inicial de los futuros docentes. Por ello, se presenta una definición de los términos que pueda ser común a ambos contextos para que sea posible la concordancia y transferibilidad del aprendizaje en la formación inicial del profesorado. Además, se presenta un ejemplo de actividad en el marco de una asignatura y con la terminología adecuada.

Reflexión sobre la evaluación en la formación inicial del profesorado en España. En búsqueda de la concordancia entre dos mundos 
Palabras clave: competencia; terminología; evaluación; calificación; formación inicial del profesorado

\begin{abstract}
This article analyzes and seeks a solution to the lack of agreement between the terminology used in the university context and that used in the non - university context. After analyzing the trajectory of assessment terminology in the educational context since 1990 and verifying that the terms of evaluation used by the authors, that are referent in the university field, have nothing to do with educational terminology, it reveals the incoherence of the initial formation of future teachers. Therefore, a definition of the terms that is common to both contexts is presented, in order to establish a concordance in the initial teacher training. In addition, an example of activity in a subject with the appropriate terminology is presented.
\end{abstract}

Keywords: competence; terminology; assessment; qualification; initial teacher training

\title{
Resumo
}

Este artigo analisa e procura uma solução para a falta de acordo entre a terminologia utilizada no contexto universitário e que a utilizada na não - contexto universitário. Depois de analisar a trajetória da terminologia de avaliação no contexto educacional desde 1990 e verificar que os termos de avaliação utilizado pelos autores, que são referência no campo universitário, nada têm a ver com a terminologia educacional, revela a incoerência da formação inicial de futuros professores. Portanto, uma definição dos termos que é comum a ambos os contextos é apresentada, a fim de estabelecer uma concordância na formação inicial de professores. Além disso, um exemplo de atividade em um assunto com a terminologia adequada é apresentada.

Palavras-chave: competencia; terminología; avaliação; qualificação; formação inicial de professores

\section{Introducción}

El Espacio Europeo de Educación Superior (EEES) comienza su andadura definitiva con la "Declaración de la Sorbona" el 25 de mayo de 1998, dando inicio al Proceso de Convergencia y estableciendo el plazo de implantación en el año 2010. 
En España, la contribución del sistema universitario se llevó a cabo a través de las adaptaciones legislativas correspondientes (LOU, 6/2001; LOU, 4/2007; R.D. 1044/2003; R.D. 1125/2003; R.D. 55/2005; R.D. 56/2005), con la finalidad de integrarse competitivamente junto a los mejores centros de Enseñanza Superior europeos.

La ordenación del EEES en España y la incorporación del concepto de competencia al sistema educativo universitario se ha vinculado con

propiciar la consecución por los estudiantes de una formación universitaria que aúne conocimientos generales básicos y conocimientos transversales relacionados con su formación integral, junto con los conocimientos y capacidades específicos orientados a su incorporación al ámbito laboral (RD 55/2005: 2842),

lo que evidencia la intención de proporcionar al alumnado una formación de calidad acorde con las necesidades que la sociedad demanda.

En la búsqueda de esta formación de calidad, los docentes se sitúan como una pieza clave sobre la que intervenir. Como destacan Coraggio y Torres (1997: 137), "no es posible seguir afirmando, en definitiva, que puede mejorarse la calidad de la educación sin mejorar sustancialmente la calidad de los docentes".

En relación a la calidad docente, la Ley Orgánica de Universidades (LOU, 2001) requería transformar los procesos de evaluación que desarrolla el profesorado. Del mismo modo, apenas se discute ya que la evaluación es unos de los condicionantes fundamentales del aprendizaje (Álvarez, 2005; Biggs, 2005; Brown y Pickford, 2013), ni que la mejora de los procesos de evaluación lo facilita e incrementa de forma significativa. Y en este sentido, Rodríguez-Gómez y Ibarra-Sáiz, (2015) comentan el cambio de paradigma pasando del basado en corrientes conductistas, donde la evaluación se ha reducido a producir calificaciones poco o nada útiles en relación a la mejorar de su proceso de aprendizaje (Ibarra, Sáiz y Rodríguez-Gómez 2010), hacia uno emergente sustentado sobre la base del constructivismo donde los procesos de retroalimentación entre iguales y la autoevaluación son fundamentales.

Por tanto, aunque se haya comprobado que las transformaciones de la evaluación en el ámbito educativo son lentas (Biggs, 2005; Brown y Glasner, 1999; Knigth, 2005; Navarro, et al., 2010) y complejas (Algozzine, et al., 2004; Emery, 
Kramer y Tian, 2003; Escudero, Pino y Rodríguez, 2010), parece necesario que éstas se produzcan.

La perpetuidad de los procesos de educación bancaria establecidos por Freire (Biggs, 1999), en los que el alumnado sigue siendo un mero receptor de información y conocimiento, parece estar impidiendo que la evaluación deje de centrarse exclusivamente en la calificación final y se favorezcan los procesos de enseñanza y aprendizaje con una mayor implicación y regulación por parte del propio alumnado (Tejedor, 1998; Palacios, y López-Pastor, 2013). En palabras de Dochy, Segers y Dierick (2002), se trataría de conseguir pasar de la "cultura del examen" a la "cultura de la evaluación", entendiendo esta última como una evaluación formativa, con la intención de mejorar el aprendizaje de los alumnos y favorecer, de este modo, su implicación en los procesos de evaluación (Palacios, y López-Pastor, 2013). Como comentan estos mismos autores, la confusión terminológica básica en relación a los términos evaluación y calificación genera parte del problema. Por ello, si pretendemos utilizar una metodología que favorezca la implicación del alumnado en el proceso de aprendizaje, parece imprescindible desarrollar una terminología coherente que aleje cualquier atisbo de duda cuando hablemos de la valoración del proceso de enseñanza y aprendizaje; tanto desde la perspectiva del alumnado como de la del docente o de su programación.

Un contexto óptimo para transformar las prácticas evaluativas es en la formación inicial del profesorado (FIP), con independencia del país en que se lleve a cabo. El punto de partida para esta transformación deben ser las concepciones previas que tienen los futuros docentes sobre la evaluación. Así, diferentes autores comentan la importancia de estas concepciones previas (Pontes, Serrano y Poyato, 2013; Pontes y Puyato, 2014), frecuentemente teñidas de pesimismo como en el caso de la educación secundaria obligatoria (Pontes, Poyato y Oliva, 2014). Por ello, autores como Palacios y López-Pastor (2013) sostienen que es necesario predicar con el ejemplo y aplicar al alumnado universitario buenos procedimientos e instrumentos de evaluación, y que además puedan ser utilizados por estos alumnos en su futura labor docente.

Parece que el alumnado universitario considera que la FIP, en relación a la evaluación que se lleva a cabo en el ámbito no universitario, cumple muy pocas de las 
características que debería transmitir (Porto, 1998; Trillo, 2005). Según Palacios y López-Pastor (2013: 284), esto refleja el inmovilismo didáctico y pedagógico que predomina en las facultades y centros de FIP en España y del nefasto efecto que esto genera en los niveles no universitarios del sistema educativo español, dado que los profesores tienden a utilizar en su docencia los mismos métodos de enseñanza y evaluación que utilizaron con ellos cuando eran alumnos. Pero incluso, asumiendo y aceptando los enormes esfuerzos realizados por una parte importante de profesorado universitario, en muchas ocasiones es habitual que los docentes, tras su formación inicial, enseñen como ellos aprendieron en su etapa de alumnos o imiten a compañeros más experimentados (Marcelo y Vaillant, 2009). Estos aspectos, que ya comentaban hace más de una década Fernández-Pérez (1989) o Tejedor (1998), no parecen haber cambiado demasiado, aun con la implantación completa del Espacio Europeo de Educación Superior. La educación superior debe estar orientada al desarrollo de competencias profesionales (transversales y específicas) y no solo a la acumulación de conocimientos (Silva y López-Pastor, 2015).

Centrados en España en la última década, se observa un creciente interés en la docencia universitaria por conseguir desarrollar las competencias del alumnado a través de su implicación en los procesos de evaluación (Arribas, Carabias y Monreal, 2010). Numerosos autores comentan la importancia del fomento de la participación del alumnado en los procesos de evaluación (Álvarez, 2003; Bain, 2005; Boud, 1995), y parece demostrado que implicar al alumnado en estos le proporciona un mayor aprendizaje, una mayor adquisición de competencias y un mayor rendimiento académico (Boud, 1995; Boud y Falchikov, 2007; Fernández-Balboa, 2005; LópezPastor, 2006, 2008; López-Pastor, et al., 2009; Manrique, et al., 2010; Santos, Martínez y López-Pastor, 2009). En esta misma línea, son varios los colectivos de docentes que con sus experiencias demuestran que los procesos de evaluación formativos y compartidos pueden mejorar los procesos y resultados de aprendizaje. Ejemplos de estos colectivos los encontramos en el grupo de investigación "EVALfor", creado en 1997, o la Red de Evaluación Formativa y Compartida en Docencia Universitaria, creada en 2005.

Con todo, uno de los principales retos a los que se enfrenta la FIP sigue siendo mejorar su transferencia a contextos reales de aplicación. Como exponen Camacho y 
Padrón (2006: 211), existe una "enorme separación entre la formación recibida y las exigencias de un desempeño eficaz e innovador". Se podría pensar que la implicación del alumnado universitario en los procesos de evaluación estaría ayudando a salvar esta enorme brecha, como ya hemos comentado. Pero como suele ocurrir, incurrimos en una autocomplacencia desde la universidad al considerar que, en relación a un determinado tema, hemos resuelto el problema por el mero hecho de involucrar al alumnado y, en cierto modo, implicarle en el éxito o el fracaso del proceso de aprendizaje. Sinceramente, ¿es suficiente?

Analicemos el caso que nos ocupa y la importancia que tiene en la sociedad actual enseñar al alumnado universitario conocimientos y aprendizajes transferibles al ámbito profesional. Concretamente, en este artículo nos centramos en la concordancia terminológica del vocabulario implicado en los procesos de evaluación. Considerando que, si nosotros fuésemos capaces de aclaramos en el marco universitario y utilizar unos términos comunes asociados a conceptos consensuados, ésta sería una contribución relevante para facilitar la transferencia entre la FIP y la futura práctica profesional de nuestro alumnado.

Son varios los autores que han realizado propuestas terminológicas $\mathrm{y}$ conceptualizaciones relacionadas con la evaluación (Hamodi, López-Pastor, y LópezPastor, 2015; Ibarra, y Rodríguez, 2010; Ibarra, Rodríguez, y Gómez, 2012; PérezPueyo, Julián, y López-Pastor, 2009; López-Pastor, et al., 2009). La dificultad surge cuando este vocabulario no es coincidente con la concepción terminológica planteada por la administración no universitaria (e.g., Gobierno, Comunidades Autónomas). En consecuencia, cuando los futuros docentes transfieren la terminología y conceptos relativos a la evaluación que han asimilado en su FIP a un contexto real, estos no son coincidentes con los utilizados en dicho contexto y generan equívocos y problemas de comprensión. Por ello, sería importante unificar los términos y conceptos utilizados en el ámbito de la docencia universitaria (Álvarez, 2009; Gullickson, 2007) y no universitaria (Pérez-Pueyo y López-Pastor, 2009).

A partir de estas consideraciones, este artículo pretende: (a) Analizar la incoherencia terminológica existente entre la evaluación universitaria y de la educación obligatoria en España, y (b) Proponer una concordancia de términos que permita 
conexionar de manera coherente el marco de la evaluación de las enseñanzas universitarias y no universitarias en relación a la FIP. Asimismo, se incluye una propuesta de intervención con ejemplos concretos de aplicación en el ámbito universitario, transferibles al no universitario.

\section{Terminología sobre evaluación utilizada en contextos universitarios y no universitarios en España}

España, desde la reforma educativa establecida en 1990 que planteó una revolución terminológica sobre evaluación, apenas ha evolucionado en todo este tiempo. Sin embargo, aunque hubiese sido sencillo esta terminología, en la FIP se ha enfocado desde una gran variedad de conceptualizaciones, presentando evidentes incoherencias que nada ayudan al futuro docente y a su alumnado. En este sentido, dejaremos a un lado las comparaciones y controversias generadas en el contexto universitario para centrarnos en aquello que verdaderamente es objeto de este artículo, analizar el contexto educativo y proponer una unificación de términos que conecten el marco de la evaluación de las enseñanzas universitarias y no universitarias en relación a la FIP. Parece lógico que la terminología que utilicemos en el ámbito universitario sea coincidente con la que se utiliza en el ámbito escolar si pretendemos que la formación que proporcionemos a nuestro alumnado universitario sea eficaz y coherente.

\subsection{Las enseñanzas no universitarias: recorrido de la terminología desde 1990}

Desde la entrada en vigor de la Ley Orgánica 1/1990, de Ordenación General del Sistema Educativo, hasta la actual Ley Orgánica 8/2013, para la Mejora de la Calidad Educativa, el sistema educativo español ha incorporado al vocabulario docente una serie de términos y conceptos relacionados con los procesos de evaluación y calificación. Así, en 1992 los Materiales para la Reforma, denominados popularmente "Cajas Rojas", determinaban que "una vez establecido lo que se considera fundamental evaluar (criterios de evaluación), será necesario determinar los procedimientos mediante los cuales obtener la información necesaria, en relación al proceso de aprendizaje [...] habrá que decidir los instrumentos de evaluación" (MEC, 1992c: 65). Como se puede comprobar, aquí aparecen vinculados por primera vez tres términos: criterios de evaluación, procedimientos de evaluación e instrumentos de evaluación. 
Y en 1996, el Real Decreto 83/1996, por el que se aprueba el Reglamento Orgánico de los Institutos de Educación Secundaria, establecía, en relación a los elementos de las programaciones didácticas, que cuando sea necesario transformar la evaluación en una calificación deberán concretarse "los procedimientos de evaluación del aprendizaje de los alumnos [...] y los criterios de calificación que se vayan a aplicar" (art. 68.2 f, g). En este caso, comprobamos que se incorporan dos nuevos términos: instrumentos de calificación y criterios de calificación, ya que el primero surge de la aparición del segundo.

Veamos estos términos. Comenzaremos por los criterios de evaluación, ya que es habitual asignarle a este término diferentes conceptos y significados. Los criterios de evaluación se establecen de manera prescriptiva por la administración educativa, permitiendo determinar los aspectos que deben tenerse en cuenta para valorar las capacidades expresadas en los objetivos (MEC, 1992: 32) y estableciendo el tipo y grado de consecución de los aprendizajes (MEC, 1996, pp. 49 y 64). Estos aspectos se repiten en la legislación posterior (RD 1631/2007) incorporando, además, que se convertirán en el referente de las competencias básicas, ahora denominadas clave (LOMCE, 2013).

Con la aprobación de la LOMCE (2013, art. 6,2,f), los criterios de evaluación determinan el grado de adquisición de las competencias clave y del logro de los objetivos de cada enseñanza y etapa educativa; destacando cuáles son para cada área/materia y curso, y encontrándose explicitados en los reales decretos de currículo básico y en los decretos del currículo de las comunidades autónomas.

En relación a la programación de aula y el desarrollo de las unidades didácticas, el MEC (1996b) considera que en estas "los objetivos didácticos, que funcionan como criterios de evaluación de la unidad didáctica, determinan el tipo y grado de consecución" (MEC, 1996: 61), lo que implica que requieren unos procedimientos de evaluación (Pérez-Pueyo, y López-Pastor, 2010). Por todo ello, y como señalan estos mismos autores, "cuando sea necesario transformar la evaluación en una calificación deberán concretarse los procedimientos en unos instrumentos de calificación con sus respectivos criterios de calificación” (RD 83/1996: art. 68.2 f y g) y, por lo tanto, las unidades didácticas no deben tener criterios de evaluación. En 
consecuencia y asentando conceptos, el Ministerio, en un intento de desarrollar un enfoque coherente, determinó excluir los criterios de evaluación como parte de la unidad didáctica, incorporando en su lugar actividades de enseñanza y aprendizaje que serán utilizadas como "actividades de evaluación" (MEC, 1996:34). Estas actividades de evaluación serán evaluadas mediante instrumentos de evaluación y calificación, añadiendo posteriormente los "criterios de calificación" como vía de concreción de la propia calificación (MEC, 199b: 61). Por ejemplo, los niveles de logro de una rúbrica pueden ser los criterios de calificación si se les otorga un valor cuantitativo para establecer la calificación de la actividad a la que se apliquen.

Por otra parte, el Real Decreto 276/2007, por el que se aprueba el Reglamento de ingreso, accesos y adquisición de nuevas especialidades en los cuerpos docentes, así como en las convocatorias de oposiciones de maestros y profesores de secundaria, establece que las unidades didácticas deben contener como mínimo los siguientes elementos: "objetivos, contenidos, actividades de enseñanza y aprendizaje y procedimientos de evaluación" (RD 276/2007; art. 21.2.2B). Como puede comprobarse, los procedimientos de evaluación continúan siendo uno de los elementos exigidos, al menos, para la elaboración de las unidades, lo que corrobora la actualidad de todo lo planteado desde 1990. Por ello, a los futuros docentes se les debería enseñar este tipo de aspectos en la universidad.

En este sentido, el termino procedimientos de evaluación puede ser definido como los tipos o maneras de obtener información sobre el proceso y el producto realizado por el alumnado y

se van a emplear para evaluar los aprendizajes de los alumnos al principio, durante y al final de cada ciclo o curso; o bien concretar más, de forma que se especifiquen los instrumentos que se van a aplicar en cada Unidad didáctica [...] Los procedimientos elegidos estarán siempre al servicio de los objetivos que se persiguen y de la información que se quiere recoger. (MEC, 1996: 59-60)

Los procedimientos de evaluación utilizan instrumentos de evaluación para su desarrollo. Por ello, en 1996, en el libro de Programación de Secundaria se concretaban los instrumentos, aunque se mezclaban producciones y actividades con estos (deberíamos entender que lo que aparece entre paréntesis son los instrumentos de los procedimientos que se identifican delante del mismo). 
Observación sistemática del trabajo en el aula (listas de control, diarios de clase, escalas de observación...). Análisis de las producciones de los alumnos (orales, escritas, de expresión plástica o musical, tecnológica...). Intercambios orales con los alumnos (debates, entrevistas, puestas en común...). Pruebas específicas (objetivas, abiertas, resolución de problemas...). Cuestionarios (de detección de conocimientos previos, de autoevaluación...): grabaciones (en magnetófono o vídeo, para su posterior análisis); etc [....] Además de autoevaluaciones y coevaluaciones (MEC, 1996: 59-60).

Por ello y a modo de ejemplo, si la Observación sistemática es un procedimiento que concreta la evaluación de una actividad como la participación diaria en clase a través de un instrumento como la listas de control o las escalas de observación.... Los debates no son un instrumento del procedimiento Intercambios orales con los alumnos, sino la producción que se genera de la actividad solicitada. Para evaluar el debate podríamos utilizar como instrumento una rúbrica o una escala de valoración.

En el año 2009, se define el término instrumentos de evaluación, por ejemplo en la Orden EDU/888/2009, como "todos aquellos documentos o registros utilizados por el profesorado para la observación sistemática y el seguimiento del proceso de aprendizaje del alumno" (art. 3.1). En este sentido, quizás la inclusión de los términos documentos o registros podría genera confusión, al poder entenderse por documento aquello que presenta un alumno para demostrar su aprendizaje (por ejemplo, un cuaderno o un portafolio) y registro, aquel que recoge la valoración (la plantilla utilizada por el profesor). Sin embargo, entendidas de este modo, serían dos cosas diferentes y no corresponderían al término instrumento. Expliquemos por qué.

Si el instrumento debe recoger o dar forma a los criterios de evaluación de la actividad (le ponemos el complemento a criterios de evaluación "de la actividad" para no confundir términos como veremos más adelante) (o de calificación) para la valoración de una producción. Por ejemplo, un portafolios (la concreción de esta producción en una actividad cuando el docente establezca los requisitos de la misma) no se debería confundir con el instrumento que se utilizaría para calificarlo (lista de control, rúbrica o escala de valoración, entre otras), y que contendría los criterios de calificación (aspectos a valorar y niveles de logro). Por ello, en este caso, documentos o registros no debemos entenderlos como cosas diferentes sino como maneras de recoger y concretar la información a valorar. 
Así, el cuaderno, el portafolio o el e-portafolio serían producciones que se llevan a cabo realizando la actividad que determina el profesor con una serie de condiciones, y que se valoran a través de documentos o registros (por ejemplo, rúbricas o escalas, entre otras) que denominamos instrumentos de evaluación. Más adelante profundizaremos y ejemplificaremos estos términos. La figura 1 intenta aclarar la relación entre los términos identificados en el ámbito educativo.

Presentamos un criterio de evaluación del RD 1105/2015 "Utilizar eficazmente las Tecnologías de la Información y la Comunicación en el proceso de aprendizaje, para buscar, seleccionar y valorar informaciones relacionadas con los contenidos del curso, comunicando los resultados y conclusiones en el soporte más adecuado" (p.485). Se concreta una actividad como puede ser Elaborar un e-Portafolio que recopile los conocimientos adquiridos sobre una determinada temática. Por lo que la producción es el e-Portafolio. En este caso, el procedimiento de evaluación es el Análisis de la producción, el cual se concreta a través de un instrumento de evaluación que en este caso es una escala de valoración (Pérez-Pueyo, 2015a). Su utilización para la calificación, lo convierte automáticamente en instrumento de calificación y los niveles de logro establecidos y asociados a una valoración numérica identifica los criterios de calificación.

\section{Criterio de evaluación}

\section{Actividad}

Producción

Procedimiento de evaluación

Instrumento de evaluación

Instrumento de calificación

Criterios de calificación
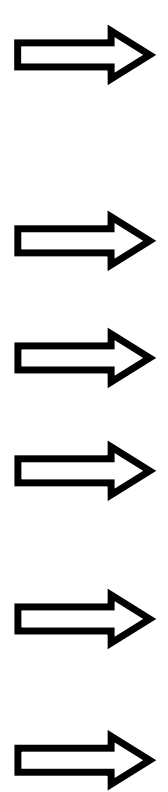

Utilizar eficazmente las Tecnologías de la

Información y la Comunicación en el proceso de aprendizaje, para buscar, seleccionar y valorar informaciones relacionadas con los contenidos del curso, comunicando los resultados y conclusiones en el soporte más adecuado

\section{"Elaborar un e- Portafolio que..."}

\section{e- Portafolio}

Análisis de la producción

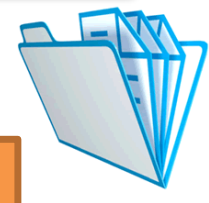

Escala de valoración

Cuantificación de los niveles de logro

Figura 1. Conceptos relacionados con el proceso de evaluación y calificación

Reflexión sobre la evaluación en la formación inicial del profesorado en España. En búsqueda de la concordancia entre dos mundos 
Resumiendo, los términos que la legislación educativa utiliza de manera sistemática son: criterios de evaluación, procedimientos de evaluación, instrumentos de evaluación, instrumentos de calificación y criterios de calificación, concretados a través de las actividades de evaluación o calificación.

\subsection{Análisis comparado de la terminología con las enseñanzas universitarias y referencias de autores}

En España, desde la aprobación de la Ley Orgánica 6/2001, de Universidades, ni en esta ley ni en la Ley Orgánica 4/2007, de 12 de abril, por la que se modifica, se encuentra normativa general alguna que identifique los términos o conceptos relativos a la evaluación. Sin embargo, las universidades, en sus respectivos desarrollos normativos, sí contemplan estos aunque de forma desigual y nada consensuada. En este sentido, el Proyecto SISTEVAL, para el estudio de los recursos respecto al establecimiento de un sistema de evaluación del aprendizaje universitario basado en criterios, normas y procedimientos públicos y coherentes confirma esta falta de consenso (Ibarra, Rodríguez, Cotrina, García y Del Barco, 2006). De hecho, son escasas las universidades que en sus estatutos recojan de forma explícita que los docentes deben explicitar los procedimientos de evaluación y criterios de corrección de exámenes. Ante esta falta de definición por parte de la administración, seguidamente analizaremos diferentes autores que son referentes en esta temática o han estudiado en profundidad estos aspectos. Como veremos, la inexistencia de un consenso es clara.

Rotger (1990) y Casanova (1998) identifican como instrumentos de evaluación (observación sistemática o análisis de las producciones) lo que Hamodi, López-Pastor y López-Pastor (2015) denominan técnicas en las que el alumnado no interviene, y que Rodríguez e Ibarra (2011) mezclan en un mismo concepto. Sin embargo, Pérez-Pueyo, et al (2008), Pérez-Pueyo, Julián y López-Pastor (2009) o Buscá et al (2010) diferencian claramente procedimientos de evaluación de instrumentos, estableciendo que los primeros albergan a los segundos y son los documentos o recursos a través de los cuales se consigue valorar la producción del alumnado. Por ello, se puede comprobar que la bibliografía equipara y confunde tres términos como son procedimiento, instrumento y técnica. 
Respecto a otro de los términos clásicos, el de criterios de evaluación, la bibliografía y, sobre todo, los docentes en general lo convierten en un cajón desastre para definir todo aquello que consideran relacionado con la calificación debido al carácter meramente sumativo y finalista del proceso de aprendizaje (Ibarra, Rodríguez, Cotrina, García, y Del Barco, 2006; Ibarra y Rodríguez, 2010). Parece que los docentes utilizan este término ante la falta de un vocabulario más amplio y concreto que refleje las diferencias entre unos conceptos y otros. Por ejemplo, Ibarra y Rodríguez (2010) lo relacionan con las condiciones para que la actividad sea de calidad. En un sentido completamente diferente, Buscà, Pintor, Martínez y Peire (2010) lo relacionan con la evaluación y calificación de las actividades. Y Salinas y Cotillas (2007: 8) lo relacionan con los aspectos o características que debe tener una actividad concreta como "Entrega en el plazo previsto. - Atenerse al formato establecido (extensión, índice, referencias bibliográficas...). - Referencias bibliográficas actualizadas"; e incluso le asignan porcentajes para calificar, estableciendo requisitos, aunque lo siguen denominando erróneamente evaluación

Incluso algunos colegas optan por cuantificar el valor de cada uno de esos criterios: - Entrega en el plazo previsto. (CONDICIÓN NECESARIA). Atenerse al formato establecido (extensión, índice, referencias bibliográficas...). (CONDICIÓN NECESARIA). - Referencias bibliográficas actualizadas (10\%) - Lenguaje claro y especializado (20\%) - Contenidos relevantes $(30 \%)$ - Correcta organización de los contenidos $(20 \%)$ - Organización del trabajo en equipo (Entrevista al grupo) (20\%) (2007:.9).

Como se puede comprobar, se observan enfoques completamente diferentes de un mismo término y bajo concepciones distintas.

Es necesario destacar que este hecho no se debería producir cuando estamos hablando de la formación de futuros docentes. No tener claro qué se debe enseñar y cómo se debe denominar no dice demasiado de la formación que proporcionamos.

Por ello y en relación a las evaluaciones que se llevan a cabo en la FIP, se advierten dos problemas claramente diferenciados, (a) la desacertada equiparación de los conceptos evaluación y calificación, que impide que el alumnado se involucre en su propio aprendizaje si no se acepta que son diferentes y que en el proceso de evaluación tiene mucho que decir y aportar el alumnado, y (b) la errónea interpretación de lo que 
significa criterio de evaluación en sí mismo. En ambos casos, se impediría la utilización de términos asociados que son diferentes por la asimilación que se haría de los mismos.

En relación al primer problema, López-Pastor (2009) aclara la diferencia de ambos conceptos estableciendo que la evaluación implica el proceso de obtención de información con la intención de mejorar el aprendizaje del alumnado, mientras que la calificación es el proceso final de representación numérica y sintética del resultado. Este último concepto es el más utilizado debido a que se desarrollan modelos reproductivos en los que no se otorga la importancia necesaria a la evaluación. Sin embargo, intentaremos demostrar que la evolución en los procesos de participación del alumnado en la evaluación han generado que la representación numérica y sintética del resultado, lejos de ser un mero proceso finalista, puede ser utilizada como orientación durante el proceso de evaluación y puede ser útil para implicar al alumnado en la toma de decisiones.

En relación al segundo problema, el propio significado de criterio de evaluación en el ámbito uiversitario, Ibarra y Rodríguez (2010) lo definen como "la condición que debe cumplir una determinada actividad, actuación o proceso para ser considerada de calidad o el principio (norma o idea) de valoración en relación al cual se emite un juicio valorativo sobre el objeto evaluado" (2010: 453). Sin embargo, si lo comparamos con la correspondencia del término y el concepto en el contexto escolar vista anteriormente, nada tiene que ver, ni por especificidad ni por concreción (RD 83/1996; LOE, 2006; LOMCE, 2013). Además, aunque estos autores lo definan así, el análisis que Ibarra, Rodríguez, Cotrina, Garcí y Del Barco (2006) realizan de ocho universidades españolas respecto a la terminología utilizada, constata que el uso de este término se vincula a porcentualizaciones, procedimientos, instrumentos o criterios de calificación, entre otros, alejados de su definición.

Podemos entonces plantear que el concepto de criterio de evaluación tiene interpretaciones diferentes en función del contexto. En el universitario, se vincula a una actividad o, incluso, a una asignatura; sobre todo, cuando se equipara evaluación con calificación. Sin embargo, en el ámbito escolar, es un elemento curricular que es definido prescriptivamente por el currículo y parece en su redacción un objetivo que determina el tipo y grado de aprendizaje durante una etapa o curso; nada que ver con la 
concreción para valorar una actividad, aunque algo relacionado cuando se vincula a los aspectos generales para la calificación de una asignatura o materia.

Aunque en el marco universitario de la FIP existe algunos autores que sí presentan una propuesta terminológica con relacionada directamente con el contexto escolar (Pérez-Pueyo, et al., 2008; Pérez-Pueyo, Julián y López-Pastor, 2009), estas están poco extendidas. Sin embargo, parece evidente que el problema no se encuentra exclusivamente en la terminología que se emplea en la universidad, sino en los enfoques metodológicos que ésta desarrolla. Como comentan Ibarra y Rodríguez (2010) o Palacios y López-Pastor (2013) es necesaria una sustancial modificación de la normativa que regula la evaluación en las universidades para que se desarrolle una evaluación orientada al aprendizaje, ajustada a las actividades auténticas con procesos formativos que proporcionen retroalimentaciones que favorezcan la mejora de dicho aprendizaje. No obstante, en ambos casos, los autores no abordan el problema de que en la FIP, además, es importante que exista una relación directa con el contexto de desarrollo de la labor profesional para la que se forma al universitario. Si se pretende involucrar al alumno en el aprendizaje, para que sea real la adquisición de competencias y trasferible al contexto escolar cuando ejerzan su futura labor docente, parece coherente que la terminología en relación a la evaluación sea homogénea.

En este sentido, pueden existir diferentes opciones de actuación. Veamos tres posibilidades: (1) Que el ámbito universitario termine de consensuar una terminología y que se preocupe de transferirla al ámbito no universitario, involucrándose en los procesos de diseño de normativas, de legislación educativa y en la formación permanente del profesorado; (2) Que aunque la universidad establezca una terminología común para todo el espacio universitario, la vinculada a los estudios conducentes a la docencia en el ámbito no universitario (Facultades de Educación) sea coherente con la que su alumnado deberá utilizar en un futuro próximo; y (3) Que ambos contextos se relacionen y hagan bueno ese nuevo concepto de transferibilidad del conocimiento desde la investigación de la realidad cotidiana del contexto escolar realizando propuestas coherentes que se puedan llevar a la práctica de manera generalizada, clara y adecuada. ¿Cuál elegiremos? 


\section{Aclaración de conceptos: propuesta para el consenso y la coherencia terminológica en la FIP}

En este caso, tras una primera aproximación (Pérez-Pueyo, Julián, y López-Pastor, 2009), presentamos una aclaración terminológica actualizada y coherente con el marco no universitario que posibilite su consenso con el universitario o, al menos, plantee una propuesta que sea coherente con el contexto escolar permitiendo que en la FIP se desarrollen aprendizajes trasferibles a la futura práctica profesional del alumnado.

Para comenzar, es imprescindible aclarar varios de los conceptos que están implicados y asociados a evaluación y calificación en cualquier etapa educativa:

a) Los Requisitos para la evaluación son aquellos aspectos o condiciones cuyo cumplimiento da derecho al alumnado a realizar las actividades, a que le sean valoradas, a realizar las siguientes que estuvieran establecidas, o a formar parte de una vía evaluativa. En este sentido, si hablamos de calificación, también existirán requisitos para la calificación, los cuales se circunscribirán a los requerimientos y restricciones que condicionan la utilización de todas y cada una de las actividades de calificación, y la aplicación de sus respectivos porcentajes respecto del valor total. Ejemplos de requisitos podrían ser: la asistencia a prácticas para tener derecho a la realización del examen escrito; la superación de un mínimo de puntos en cada apartado de un trabajo o examen para poder obtener una calificación global con la intención que se demuestre un conocimiento o dominio básico en todas las partes; en una tarea que contenga varias actividades, que sea necesario superar la actividad anterior para poder afrontar la siguiente; que deba de existir una coevaluación entre iguales o que deban de proceder de una manera determinada en un trabajo o tarea, etc... Estos requisitos también podrían darse en la asignatura o materia para la calificación final pero estarían vinculados a los criterios de calificación de la asignatura, como veremos posteriormente.

b) La Actividad de evaluación identifica el tipo de prueba o producción que se va a solicitar para la comprobación de los conocimientos, capacidades y competencias del alumnado; así como los requisitos que debe cumplir. En este sentido, podemos decir que la actividad es la concreción de un tipo de producción a través de una serie de requisitos que se deben cumplir. Si la actividad es para calificar se denomina Actividad de calificación. Las Actividades pretenden comprobar si las competencias y/u objetivos 
planteados son alcanzados por el alumnado. De hecho, estos pueden requerir más de una actividad para comprobar si se han alcanzado las competencias; o en otros casos, una actividad puede estar relacionada con las de una competencia y/u objetivo; además de poder estar estrechamente relacionado con una metodología. Así, y aunque es muy habitual que sean considerados instrumentos, como señalaba el propio Ministerio de Educación español en determinados momentos (MEC, 1992), en realidad, por ejemplo un portafolio o un informe del proceso de aprendizaje de una asignatura, no son más que producciones que se concretan en las actividades que solicitamos al alumnado y nos permiten comprobar los objetivos planteados y las competencias requeridas al alumnado (figura 1). Otros ejemplos de producciones, que no instrumentos, y que se concretan en la actividad solicitada al alumnado son: el trabajo escrito que representa la investigación realizada en relación a una temática, la exposición oral de esa investigación, el análisis de videos para identificar y justificar errores cometidos, los debates para que el alumnado demuestre su capacidad para justificar y argumentar desde diferentes posiciones, o un video-tutorial de un aprendizaje adquirido, entre otro muchos (ver múltiples ejemplos para el contexto escolar en www.grupoactitudes.es y para el universitario en ifahe.unileon.es .

c) El Procedimiento de evaluación es el "marco o ventana" a través del cual miramos y que condicionará el conjunto de instrumentos (herramientas) seleccionados para valorar el grado de consecución de las competencias y/u objetivos planteados y que se relaciona con la actividad de evaluación. Entre los diferentes procedimientos, que otros denominan técnicas (Hamodi, López-Pastor, y López-Pastor, 2015; Rodríguez, y Ibarra, 2011), encontramos la observación sistemática, el análisis de las producciones, los intercambios orales con el alumnado o las pruebas específicas, entre otras, al igual que las denomina el Ministerio español (MEC, 1992).

c.1) En relación a la aplicación de la observación sistemática, podríamos decir que utilizamos esta "ventana" para analizar situaciones que no se concretan (en general) en una producción tangible y que requieren de su valoración por la relevancia en el proceso de aprendizaje como: la participación diaria en los trabajos de grupo o en las prácticas de laboratorio, la intervención en clase, las aportaciones que se hacen en contextos de participación grupal, etc. Aunque otra 
cuestión serán los instrumentos que se pueden utilizar para registrar esa observación.

c.2) En relación al análisis de las producciones del alumnado, aclarar que, en realidad, son la valoración de las producciones realizadas por el alumnado y que han sido requeridas y concretadas por el profesor a través de las condiciones establecidas en la actividad. Ejemplos de producciones son: un cuaderno de campo o uno digital, los resúmenes, las monografías, las producciones motrices o dramáticas, los montajes finales, los informes, los portafolios o un trabajo de investigación, y sólo son algunos de los innumerables ejemplos de los tipos de producciones. La actividad sería la realización de un resumen con una serie de condiciones como: extensión máxima de 300 palabras, con 4-5 palabras clave, que desarrolle las ideas esenciales del objeto resumido, etc (el resumen es la producción). Y posteriormente, con el instrumento adecuado (rúbrica, escala de valoración, lista de control...), podrán valorar el resultado tanto el profesorado como el alumnado (por coevaluación o autoevaluación) si se considera necesario.

c.3) En relación a los intercambios orales, en este caso podemos relacionarlo con actividades asociadas a la evaluación como los seminarios en los que se discute sobre determinadas temáticas, cuestionarios orales, mesas redondas, las asambleas iniciales o finales, los momentos de reflexión, las entrevistas mucho, poco o nada estructuradas, etc.

c.4) Y en relación a las pruebas específicas, se suelen circunscribir los exámenes escritos (tipo test, de respuestas cortas, largas, de comparación,...); las ejecuciones de dominio técnico como por ejemplo la realización de una RCP (reanimación cardiopulmonar), la práctica de laboratorio, una interpretación de una pieza musical o una prueba física incluso, dependiendo del punto de vista, una defensa oral de un trabajo, cuando se debe valorar en el acto; etc...

d) Los Instrumentos de evaluación son aquellos, vinculados a una actividad, que establecen con claridad y de modo coherente los requisitos y los aspectos a valorar e identifican los niveles de logro de cada uno. De este modo, los instrumentos permiten comprobar las capacidades y las competencias alcanzadas por el alumnado. Por ello, pueden ser definidas como aquellas herramientas que forman parte del proceso de 
evaluación, que identifican con claridad los niveles de logro exigibles y que pueden conducir al proceso de calificación. Si éste es el caso, pasarán a denominarse instrumentos de calificación, y llevarán asociados una serie de criterios de calificación y su correspondiente porcentualización proporcionando la calificación global o total (Pérez-Pueyo, Julián, y López-Pastor, 2009; Pérez-Pueyo, 2010). Los ejemplos de instrumentos han ido proliferando en las últimas décadas. La necesidad de encontrar aquel que mejor se ajusta a las necesidades e intereses del docente, de la asignatura o del enfoque metodológico provoca la búsqueda de aquellos que permiten comprobar mejor los objetivos y competencias a valorar. Además, la concreción de los mismos proporcionará un mayor grado de objetividad o, al menos, de coherencia entre lo que el docente quiere comprobar y el alumnado realizar. En este sentido, desde las clásicas listas de control con sus respectivos sí o no (o sí, no, a veces), las fichas de seguimiento o los registros de control, hasta las recientes rúbricas, escalas de valoración, escalas descriptivas, entre otras, nos permiten elegir el tipo de valoración que pretendemos obtener.

Llegados a este punto debemos realizar una aclaración. Como comentamos anteriormente y matizando la definición de López-Pastor (2009), la representación numérica y sintética del resultado no tiene por qué ser necesariamente la calificación si se desarrolla durante el proceso. En este sentido, la utilización de escalas de valoración en las que el alumnado, durante el proceso, puede calcular el valor final de su trabajo si se entregase en ese momento y proporcionando una representación numérica y sintética, no será calificación; a excepción de que el alumno decida no mejorar ese trabajo hasta el día de la entrega final en el que será realmente calificado y aparecerá en el acta. Este tipo de instrumentos y la información que proporciona al alumnado, no sólo favorece la capacidad de mejorar su aprendizaje sino de regular el propio proceso.

e) Los criterios de evaluación, al haber sido definidos por el Ministerio de España (como se expuso anteriormente) ya tienen su propia conceptualización y es a la que nos remitimos. Sin embargo, es evidente que los docentes universitarios tienden a utilizar este término de forma habitual, aunque debemos recordar que no existe unanimidad en la definición, como hemos expuesto. Por ello, si buscamos la coherencia y transferibilidad del aprendizaje, quizás deberíamos no utilizar este término en las guías docente y sustituirlo por el que realmente defina el aspecto que pretendemos describir. 
Cuando un instrumento se utiliza para evaluar y no para calificar, los criterios que se utilizan se deberían denominar criterios de evaluación de la actividad, los cuales indicarán los niveles de logro realizados (el apellido "de la actividad" ayudará a no confundirlo con el establecido por la administración educativa para cada curso y materia).

f) Los criterios de calificación pueden ser entendidos desde diferentes puntos de vista, lo que nos obligará a añadirle un nuevo "apellido", por ejemplo de asignatura o de actividad.

f.1) Los criterios de calificación de la actividad son las normas que un instrumento de calificación concreto requiere para concretar el aprendizaje adquirido y proporcionar el valor numérico (puntuación) a atribuir a una actividad de calificación. Esto implica que en cada instrumento se deben identificar los criterios de calificación que permiten conocer el logro obtenido y el valor asignado al mismo. Recordar, como hemos comentado, que no siempre que un instrumento proporciona un número es necesariamente instrumento de calificación.

f.2) Los criterios de calificación de la asignatura o materia son aquellas normas que condicionan la calificación final de la misma y que suelen estar vinculadas a la porcentualización de las actividades de calificación y a los requisitos de la asignatura. Por ejemplo, una asignatura puede condicionar la calificación a la realización de una serie de actividades fundamentales o a la obtención de una nota mínima para poder superar el aprobado, aunque el cómputo global pueda ser superior a cinco.

g) La Porcentualización de las actividades de calificación es el valor sobre 100 (o la base que se establezca) que se le otorga a cada actividad de calificación. En el ejemplo de la tabla 1 se pueden diferenciar las actividades y registros de evaluación y de calificación, ya que éstas indican el porcentaje que se les confiere para la calificación final. Además, se ha indicado quién o quiénes son los responsables de realizarla.

Tabla 1.- Actividades y registros de evaluación y calificación, \% de las de calificación 


\begin{tabular}{|c|c|c|}
\hline Realizar un trabajo de investigación & $20 \%$ & Grupal \\
\hline Exponer oralmente el trabajo de investigación & $30 \%$ & Grupal \\
\hline Entregar del cuaderno de campo & $10 \%$ & Individual \\
\hline $\begin{array}{c}\text { Realizar el proceso de coevaluación de las presentaciones de } \\
\text { compañeros }\end{array}$ & - & Grupal \\
\hline $\begin{array}{c}\text { Realizar la autoevaluación de las presentaciones sobre la grabación } \\
\text { personales y del resultado global del grupo }\end{array}$ & - & Grupal \\
\hline Diseñar en grupo las posibles preguntas de examen & $10 \%$ & Grupal \\
\hline Realizar el examen escrito de preguntas cortas & $20 \%$ & Individual \\
\hline Realizar la autoevaluación y coevaluación del examen & - & Individual \\
\hline $\begin{array}{c}\text { Utilizar el diario de seguimiento intragrupal para el reparto de nota } \\
\text { individual en el grupo }\end{array}$ & - & Grupal \\
\hline Registro de anécdotas & $10 \%$ & Profesor \\
\hline
\end{tabular}

Como se puede observar, realizar un trabajo de investigación o exponerlo oralmente pertenecen al proceso de calificación otorgándoles un porcentaje en la calificación final. Sin embargo, realizar la coevalaución de las presentaciones, aunque se utilice el mismo instrumento (la escala de valoración) que para la calificación, en este caso sólo corrobora o ayuda a comprender los aspectos conseguidos o no conseguidos del trabajo realizado, aunque no repercute en la calificación final. Éste, unido a las autoevaluciones generan un proceso de evaluación triádica (Pérez-Pueyo, 2015a) fundamental para el aprendizaje y aproximación a la calificación dialogada (LópezPastor, 2009).

En conclusión, lo que hemos tratado de concretar es la posibilidad de utilizar unos términos sobre evaluación que sean claros, útiles y trasferibles entre la educación universitaria y no universitaria que nos permitan hablar un mismo idioma educativo.

\section{Propuesta de intervención y su análisis evaluativo}

Para la ejemplificación de esta propuesta nos hemos decantado por centrarnos en una competencia de carácter general, genérica o transversal (Perrenoud, 2004), de las más utilizadas en el ámbito universitario como es la exposición oral; la cual, es una dimensión o subcompetencia de la competencia lingüística (Orden ECD 65/2015) en las etapas del ámbito educativo no universitario.

Según Corredor y Romero (2008), estas exposiciones deberían ser habituales en el quehacer diario del alumnado y de hecho lo son. Sin embargo, son un tipo de actividad, con carácter claramente transversal, cuya utilización en cualquier materia no parece mejorar por el mero hecho de repetirse. La razón radica en la falta de concreción 
de cómo deberían aplicarse para que pudiesen generar aprendizaje y fuesen adecuadas para el nivel académico en el que nos encontramos.

Si bien no es la primera vez que se llevan a cabo experiencias de evaluación formativa en los procesos de exposiciones orales en el ámbito universitario (Ponce, 2001) con la intención de generar aprendizaje, la experiencia presentada combina la aplicación de un proceso de evaluación formativa en las exposiciones orales, con una evaluación triádica (Pérez-Pueyo, 2015a), a través de la triangulación de información obtenida de la heteroevaluación del docente y las autoevaluaciones y coevaluaciones del alumnado, además de la implicación del alumnado en la elaboración del instrumento de evaluación.

Respecto al instrumento de evaluación elegido, las rúbricas han sido de los más valorados habitualmente (Conde, y Pozuelo, 2007; Hafner, y Hafner, 2003) por asociar cualitativa y/o cuantitativamente criterios preestablecidos para medir las actividades (Torres, y Perera, 2010). Sin embargo, los docentes, en un intento de aumentar la objetividad del valor de los aspectos a observar, tienden a asignar porcentajes a estos y aumentar los niveles en que se pueden observar los logros del alumnado (Alonso-Cortés, et al., 2015). Por ello y con la intención de no "retorcer" el instrumento (Pérez-Pueyo, et al., 2014) nos decantamos por plantear una Escala de Valoración, en la que cada aspecto a valorar tiene un porcentaje del valor total y a cada uno de ellos se le subdivide descriptivamente en tantos niveles de logro como sea posible identificar la realización del mismo. Además, se le otorga un valor decreciente desde el máximo establecido porcentualmente al aspecto a observar, al mínimo observable. Además, se pueden establecer niveles mínimos o requisitos de realización para una evaluación positiva, los cuales son muy útiles para compensar las incongruencias generadas por la no realización de logros imprescindibles desde el enfoque global de la producción solicitada.

El siguiente ejemplo de aplicación en el ámbito universitario surge de la intención por esclarecer la relación que debe existir entre los diferentes conceptos evaluativos a través de la descripción de los mismos. Sin embargo, su transferencia al ámbito escolar también ha sido llevada a cabo, con las adaptaciones necesarias (véanse ejemplos en www.grupoactitudes.es). 
4.1. La escala de valoración como instrumento de evaluación en las exposiciones orales

A continuación se presenta una situación de aprendizaje y la actividad elegida en este caso para el contexto universitario. Proseguimos explicando la relación con los términos de evaluación propuestos y que son coherentes con el ámbito escolar no universitario. Razonamos la elección del tipo de instrumento de evaluación y calificación. Y finalizamos justificando el proceso de evaluación formativa y compartida llevado a cabo.

Situación aprendizaje: Imaginemos una asignatura de cualquier Grado o Máster en la que el alumnado deba realizar un trabajo escrito, individual o grupal y que, tras la superación del mismo, sea necesaria la defensa oral y pública del mismo delante de los compañeros.

En nuestro caso, el grupo debe preparar la exposición partiendo de Escala de Valoración de las exposiciones orales (Pérez-Pueyo, 2015b) (tabla 2) que se entrega al inicio de la asignatura, hecho que condicionará el devenir del proceso de aprendizaje. A través de un proceso de evaluación formativa en el que se llevan a cabo autoevaluaciones y coevaluaciones intragrupales con la escala se prepara la exposición final.

Tabla 2.- Escala de Valoración de las exposiciones orales (Pérez-Pueyo, 2015)

\begin{tabular}{|l|c|}
\hline ESCALA DE VALORACIÓN DE LA EXPOSICIÓN ORAL & \\
\hline Nombre: & \\
\hline COMUNICACIÓN NO VERBAL (30 puntos) & 6 \\
\hline 1. LENGUAJE CORPORAL: CONTACTO VISUAL & 5 \\
\hline Mantiene durante toda la exposición el contacto visual con las personas que le escuchan; de forma natural & 4 \\
\hline $\begin{array}{l}\text { En general, mantiene el contacto visual, aunque puntualmente mira a la pantalla o a un cierto grupo de } \\
\text { alumnos y se ayuda de los elementos audiovisuales }\end{array}$ & 3 \\
\hline $\begin{array}{l}\text { En general, mantiene el contacto visual, aunque puntualmente mira a la pantalla o a un cierto grupo de } \\
\text { alumnos y se ayuda de los elementos audiovisuales porque lo necesita para continuar }\end{array}$ & 1 \\
\hline $\begin{array}{l}\text { Mantiene el contacto visual aunque a veces mira hacia el suelo, el fondo o se queda demasiado tiempo } \\
\text { mirando sólo a un grupo de personas }\end{array}$ & 1 \\
\hline $\begin{array}{l}\text { Apenas mantiene el contacto visual o se queda excesivo tiempo con una misma persona o grupo de } \\
\text { personas durante el mayor tiempo que dura la exposición }\end{array}$ & 6 \\
\hline 2. LENGUAJE CORPORAL: GESTO -BRAZOS Y MANOS- & 5 \\
\hline Utiliza todo el tiempo el movimiento de brazos y manos de forma natural e ilustrando lo que está diciendo & 4 \\
\hline $\begin{array}{l}\text { La mayor parte del tiempo utiliza el movimiento de brazos y manos de forma natural ilustrando lo que está } \\
\text { diciendo }\end{array}$ & 3 \\
\hline $\begin{array}{l}\text { La mayor parte del tiempo utiliza el movimiento de brazos y manos pero no siempre de forma natural o sin } \\
\text { ilustrar lo que está diciendo }\end{array}$ & 4 \\
\hline Tiende a quedarse estático sin cambiar la posición & 6 \\
\hline Apenas utiliza el movimiento de brazos y manos. & 5 \\
\hline 3. LENGUAJE CORPORAL: POSTURA CORPORAL & 3 \\
\hline $\begin{array}{l}\text { Permanece de pie, mantiene piernas un poco abiertas y pies en una pequeña zona, cambiando el peso al } \\
\text { hablar de forma natural. }\end{array}$ & 6 \\
\hline Permanece de pie, mantiene piernas un poco abiertas y pies fijos, evitando movimientos oscilantes \\
\hline Permanece de pie, a veces junta o cruza los pies y realiza algunos movimientos oscilantes y repetitivos \\
\hline Estando de pie, abusa de movimientos oscilantes y repetitivos que reflejan inseguridad o desinterés \\
\hline 4. LENGUAJE PARAVERBAL: VOLUMEN & 1 \\
\hline La intensidad con que emite la voz es alta, nítida y audible. Ritmo-pausa. Voz atractiva y brillante que & 6 \\
\hline
\end{tabular}




\begin{tabular}{|c|c|}
\hline \multicolumn{2}{|l|}{ genera interés en los oyentes. Demuestra con la voz los aspectos que son verdaderamente importantes } \\
\hline Realiza casi toda la exposición de forma clara con tono de voz adecuado y con las pausas necesarias & 5 \\
\hline $\begin{array}{l}\text { En general, la intensidad con que emite la voz es alta, nítida y audible. Falta algo de atractivo en la voz y de } \\
\text { énfasis para generar un razonable interés en los oyentes }\end{array}$ & 4 \\
\hline $\begin{array}{l}\text { A veces, tiene un volumen bajo y hay que hacer esfuerzos por escucharle... O no siempre es atractiva o } \\
\text { brillante }\end{array}$ & 2 \\
\hline La mayor parte del tiempo ha utilizado un volumen bajo y apagado & 1 \\
\hline 5. LENGUAJE PARAVERBAL: ENTONACIÓN & \\
\hline $\begin{array}{l}\text { Utiliza una entonación para demostrar los aspectos que son verdaderamente importantes. Nada monótono. } \\
\text { La entonación genera interés en los oyentes }\end{array}$ & 6 \\
\hline $\begin{array}{l}\text { La mayor parte de tiempo utiliza una entonación alejada de la monotonía, y generalmente enfatizando los } \\
\text { aspectos importantes. }\end{array}$ & 5 \\
\hline Aunque suele utilizar una entonación correcta, no enfatizando los aspectos importantes. & 4 \\
\hline A veces, se percibe monotonía en su presentación & 3 \\
\hline Frecuentemente se percibe una entonación monótona que genera desinterés en los oyentes & 1 \\
\hline \multicolumn{2}{|l|}{ ESTRUCTURA Y CONTENIDO (40 puntos) } \\
\hline \multicolumn{2}{|l|}{ 6. CAPACIDAD SINTÉTICA } \\
\hline Presenta el artículo o el documento (material, videografico,...) de manera sintética y clara & 8 \\
\hline $\begin{array}{l}\text { Presenta el artículo o el documento (material, videografico,...) de manera sintética aunque con algún } \\
\text { aspecto irrelevante o innecesario }\end{array}$ & 6 \\
\hline Aunque presenta el documento o artículo, no es sintético & 4 \\
\hline No presenta no es sintético & 1 \\
\hline \multicolumn{2}{|l|}{ 7. JUSTIFICACIÓN DE LA ELECCIÓN } \\
\hline $\begin{array}{l}\text { Se entiende con claridad las razones de la elección y son justificadas (no proporciona información } \\
\text { innecesaria) }\end{array}$ & 8 \\
\hline $\begin{array}{l}\text { Se comprenden bien las razones de su elección aunque dicha justificación se podría haber hecho de } \\
\text { manera más clara o sintetizada... O hay aspectos discutibles }\end{array}$ & 6 \\
\hline Se comprenden las razones de su elección aunque algún/os aspecto/s no quede/n claro/s & 5 \\
\hline No se comprenden bien las razones de su elección/no son claras & 3 \\
\hline No presenta razones de la elección & 1 \\
\hline \multicolumn{2}{|l|}{ 8. FUNCIONALIDAD/TRANFERIILIDAD } \\
\hline Demuestra con claridad la funcionalidad/transferibilidad del mismo al ámbito docente & 8 \\
\hline Demuestra la funcionalidad/transferibilidad del mismo al ámbito docente aunque no de forma precisa/clara & 6 \\
\hline Existe confusión evidente en la funcionalidad/transferibilidad del mismo al ámbito docente & 4 \\
\hline No demuestra la funcionalidad/transferibilidad al ámbito docente & 1 \\
\hline \multicolumn{2}{|l|}{ 9. ADECUACIÓN A EDAD Y CURRICULO } \\
\hline Muestra capacidad para adecuarlo a la edad y al currículo. Lo justifica con ejemplos. & 8 \\
\hline $\begin{array}{l}\text { Muestra capacidad para adecuarlo a la edad y al currículo aunque de forma poco precisa. Ejemplos poco } \\
\text { claros }\end{array}$ & 5 \\
\hline Su intento de adecuarlo a la edad ni al currículo muestra debilidades & 3 \\
\hline No muestra capacidad para adecuarlo a la edad ni al currículo & 1 \\
\hline \multicolumn{2}{|l|}{ 10. ESTRUCTURA DE LA EXPOSICIÓN ORAL: APERTURA, CUERPO Y FINAL } \\
\hline Se respeta de manera más o menos evidente la estructura de la exposición oral & 8 \\
\hline $\begin{array}{l}\text { Se respeta de manera más o menos evidente la estructura de la exposición oral aunque se muestra } \\
\text { descompensación en el énfasis de las partes }\end{array}$ & 6 \\
\hline Se respeta la estructura de la exposición oral, aunque deja alguna parte poco concreta o poco desarrollada & 4 \\
\hline No se respeta la estructura de la exposición oral & 1 \\
\hline \multicolumn{2}{|l|}{ 11. ORIGINALIDAD (10 puntos) } \\
\hline La presentación es imaginativa y desprende creatividad. Es muy original o por la temática o por la forma & 10 \\
\hline La presentación es llamativa y original aunque a veces pierde interés y sólo puntualmente pierde interés & 8 \\
\hline La presentación es llamativa y original aunque a veces pierde interés & 6 \\
\hline La presentación es correcta: ni llamativa ni original pero cumple con lo que se pide & 5 \\
\hline La presentación es bastante aburrida y poco original & 1 \\
\hline \multicolumn{2}{|l|}{ CUALIDADES DE UN BUEN ORADOR -CONEXIÓN EMOCIONAL- (20 puntos) } \\
\hline \multicolumn{2}{|l|}{ 12. ENTUSIASMO Y MOTIVACIÓN } \\
\hline Mantiene durante toda la exposición entusiasmo y consigue motivar a los oyentes con el tema desarrollado & 8 \\
\hline $\begin{array}{l}\text { Mantiene el entusiasmo durante la mayor parte de exposición y consigue motivar a los oyentes con el tema } \\
\text { desarrollado }\end{array}$ & 6 \\
\hline A veces entusiasma/pierde y motiva/desmotiva con el tema desarrollado & 4 \\
\hline Apenas mantiene entusiasmo y motivación en los oyentes hacia el tema desarrollado & 1 \\
\hline \multicolumn{2}{|l|}{ 13. NATURALIDAD Y CREDIBILIDAD } \\
\hline Es natural y creíble & 6 \\
\hline La mayor parte del tiempo es creíble y natural & 5 \\
\hline Es natural o creíble pero no ambas cosas & 3 \\
\hline No es natural ni creíble & 1 \\
\hline 14. SIMPATÍA Y APERTURA & \\
\hline Muestra disponibilidad y cercanía. Realiza gestos abiertos y afables & 6 \\
\hline Generalmente muestra disponibilidad y cercanía. Realiza gestos abiertos y afables & 4 \\
\hline A veces muestra disponibilidad y cercanía & 3 \\
\hline
\end{tabular}

Reflexión sobre la evaluación en la formación inicial del profesorado en España. En búsqueda de la concordancia entre dos mundos 
Describimos a continuación dos de las actividades desarrolladas como ejemplos.

Actividad de evaluación: Realizar una exposición oral del trabajo en un tiempo determinado. Requisitos: La defensa del trabajo de investigación se llevará a cabo en grupo y de forma oral, en un tiempo no inferior a 10 minutos ni superior a 12. Formarán parte del grupo los mismos alumnos que realizaron el trabajo escrito cuya superación da paso a la defensa. Para ésta se deberá preparar una presentación en powerpoint o prezi que servirá de guía al profesor y a los asistentes durante la exposición.

Todos los miembros del grupo deberán saberse perfectamente la exposición completa, pues el tribunal (profesor y dos alumnos seleccionados al azar de entre los demás grupos) decidirán a sorteo el orden de exposición de los miembros del grupo 15 minutos antes del inicio. Finalizada la defensa, durante cinco minutos, se deberán responder a las preguntas realizadas por el tribunal. Las preguntas serán individuales y se harán tantas como miembros formen el grupo.

En el caso de que alguna pregunta no sea respondida, podrá ser contestada por otro miembro del grupo aunque implicará que en la nota individual final del que no respondió tendrá 0,5 puntos menos de la nota final obtenida tras el reparto (el reparto de nota se explicará a continuación). El medio punto recuperado por el compañero que respondió lo sumará a su nota individual. Para responder a las preguntas falladas se establecerá un orden interno de respuesta. Si se ha hecho un trabajo se deben poder responder a todas las preguntas relativas al mismo (no es suficiente con aprenderse una exposición).

El tribunal utilizará la Escala de Valoración de las exposiciones orales (PérezPueyo, 2015) (tabla 2) para generar la nota de la misma y que se entregó al alumnado al inicio de la asignatura. Tras la utilización individual por cada miembro, se consensuarán las valoraciones de los tres miembros para proporcionar una nota final. En caso de no conseguirlo, se hará la media de las tres en el caso de una disparidad superior a dos puntos entre la mayor y la menor. La nota obtenida se le proporcionará a los grupos para que hagan el reparto individual de la nota grupal. 
Actividad de evaluación: Utilizar el diario de seguimiento intragrupal para el reparto de nota individual en el grupo. Una vez finalizada la defensa, el tribunal proporcionará una única valoración. Esta nota es la que el grupo deberá repartir sobre la base de su autoevaluación previa, obteniéndose la nota individual cuya suma y división por los miembros del grupo debe ser igual a la calificación de la exposición otorgada por el tribunal.

Para ello, el grupo, basándose en su diario de seguimiento intragrupal (PérezPueyo, Hortigüela, y Hernando, 2014) (tabla 3) que fueron rellenando al finalizar cada sesión, deberá entregar una autoevaluación intragrupal, con estructura de informe, en la que valorarán la preparación de la defensa y en el que justificarán la nota individual de cada miembro. Esto deberán llevarlo a cabo tras un proceso de coevaluaciones, registro y asunción de responsabilidades, estableciendo diferencias de valoración de su trabajo, pues no es posible que la nota de los miembros del grupo sea igual a la establecida en la defensa. En cualquier caso, las notas de, al menos, dos miembros del grupo se deben diferenciar en 0,1 puntos y nunca en más de dos. La decisión debe ser consensuada y aceptada por todos los miembros. A este reparto final se deberán sumar o restar los puntos ganados o perdidos en la fase de preguntas.

Tabla 3.- Modelo de Diario de seguimiento intragrupal (Pérez-Pueyo, Hortigüela, y Hernando, 2014)

\begin{tabular}{|l|c|}
\hline TIPOS DE TRABAJO REALIZADO & $\mathrm{A} 1$ \\
\hline No ha presentado el trabajo encomendado & $\mathrm{A} 2$ \\
\hline El trabajo presentado y encomendado es muy deficitario respecto a lo que se esperaba & $\mathrm{A} 3$ \\
\hline $\begin{array}{l}\text { El trabajo encomendado es el esperado (no ha cometido errores de forma/ortográficos/ } \\
\text { redacción/referencias) }\end{array}$ & $\mathrm{A} 4$ \\
\hline El trabajo encomendado para hoy supera las expectativas del mismo & $\mathrm{A} 5$ \\
\hline Sus errores de forma/ortográficos/ redacción/ referencias ralentizan el resultado del trabajo & \\
\hline
\end{tabular}

\begin{tabular}{|l|c|}
\hline PARTICIPACIÓN Y APORTACIONES EN EL DEBATE INTERNO & \\
\hline Su participación en la discusión ha sido nula o muy escasa & B1 \\
\hline Ha participado pero no ha aportado demasiado & B2 \\
\hline Sus aportaciones han sido valoradas por los compañeros & B3 \\
\hline Sus aportaciones ha sido claves para la orientación/reorientación del trabajo & B4 \\
\hline
\end{tabular}

El Diario de seguimiento individual intragrupal permite conocer la valoración que los miembros del grupo establecen a cada uno de ellos durante su trabajo diario. Esta autoevaluación grupal o coevaluación intragrupal ofrece a los miembros la posibilidad de valorar el trabajo diario de cada participante para la posterior valoración final, tras la nota grupal obtenida. 
Los comportamientos observables que previsiblemente reproducirán con mayor frecuencia el alumnado se han identificado con una letra y un número, para facilitar su registro durante las sesiones (se adaptará modelo). Así, los grupos, cada día, en los últimos cinco minutos de trabajo deberán ponerse de acuerdo para que una única frase sea la que mejor identifica en trabajo realizado por cada miembro del grupo (se podrá decidir indicar hasta dos).

Esta información diaria, comparada con el registro de anécdotas del profesor y su diario, permitirá ofrecer una evaluación formativa y ayudar a continuar o reorientar el trabajo en el caso de ser necesario.

Pese a que este instrumento alude exclusivamente a la evaluación del alumnado y no incide directamente sobre su calificación, sí que se encuentra relacionado con ella, puesto que podrá ser utilizado como referente directo para los diferentes repartos de nota establecidos.

El diario que se proporciona como modelo puede y debe ser adecuado a las necesidades y características del grupo.

\subsection{Relación con los términos de evaluación}

Explicadas las dos actividades, nos centraremos en la exposición oral, identificando a continuación cada uno de los conceptos presentados anteriormente (véase Tabla 4):

Tabla 4.- Términos de evaluación y su concreción

\begin{tabular}{|l|l|}
\hline \multicolumn{1}{|c|}{ TÉRMINO } & \multicolumn{1}{|c|}{ Concreción } \\
\hline Producción & Exposición oral \\
\hline Actividad & $\begin{array}{l}\text { Realizar una exposición oral del trabajo en un tiempo } \\
\text { determinado }\end{array}$ \\
\hline Requisitos & $\begin{array}{l}\text { Para que pueda ser defendido el trabajo deberá haber superado la } \\
\text { calificación del Trabajo de Investigación con, al menos, un 5. }\end{array}$ \\
\hline Procedimientos de evaluación & Análisis de la producción \\
\hline Instrumento de calificación & Escala de valoración \\
\hline Criterios de calificación & Ver anexo I (cada uno de los niveles establecidos en la escala) \\
\hline
\end{tabular}

En este caso, la producción elegida para que el alumnado demuestre su aprendizaje es la exposición oral. Sin embargo, la actividad planteada es: Realizar una exposición oral del trabajo por el grupo en un tiempo determinado $\mathrm{y}$, en consecuencia, la aportación a la misma que realiza cada miembro de éste.

Los Requisitos para la exposición oral en la defensa pública ante tribunal es la superación del trabajo de investigación. 
Los Procedimientos de evaluación seleccionados, que en este caso son para una actividad de carácter oral, son tres: el Análisis de la producción, la Coevaluación y la Autoevaluación intragrupal.

El instrumento de calificación seleccionado en este caso es la escala de valoración (tabla 4). Y como situación particular, destacamos que el instrumento es utilizado tanto para la calificación por el docente y como por los grupos como instrumento de evaluación para coevaluar al que expone (Pérez-Pueyo, 2015). Además, también se utiliza para la autoevaluación intragrupal, durante el proceso formativo de la preparación de la exposición (Pérez-Pueyo, Hortigüela, y Hernando, 2014).

Los Criterios de calificación de la actividad pueden ser identificados en la escala. En ésta, reflejados los aspectos a valorar y asignados el valor parcial en función de la importancia que se les confiere, se identifican tantos indicadores de logro como niveles se considere en que se puede realizar el aspecto a valorar. El conjunto de aspectos a valorar, los porcentajes y sus respectivos indicadores de logro determinan los criterios de calificación (Ver la Escala de valoración en el tabla 2).

Cuando la escala es utilizada para evaluar, a los aspectos a valorar y niveles de logro los denominamos criterios de evaluación de la actividad. La razón radica en que si les denominásemos simplemente criterios de evaluación se les confundiría con el término establecido en el concepto de currículo por la administración educativa presentado anteriormente.

Respecto a la Porcentualización de las actividades de calificación, como se ha visto en la tabla 1, a la exposición oral le corresponde un 30\% del total. Sin embargo, tanto las coevaluaciones como las autoevaluaciones son actividades de evaluación y no influyen en la calificación final.

\section{Conclusiones}

Llamar a dos cosas diferentes de la misma manera, es una torpeza. Llamar a dos cosas iguales de diferente manera, en algunos casos, únicamente es una cuestión de vanidad. $\mathrm{Y}$ en este caso, no intentar ponernos de acuerdo por el bien de la formación que pretendemos impartir, establecidas las razones y justificaciones de la misma, sería imperdonable. Debemos anticipar los problemas que le conllevará al futuro docente no conocerlo y encontrarse después con la realidad del centro. Y si aceptamos la necesidad 
de hacer fácil y coherente la transferencia de conocimiento y de aprendizaje en la FIP, comprenderemos que la implicación del alumnado en el proceso de aprendizaje es imprescindible.

En este artículo, tras analizar la terminología empleada en evaluación universitaria y en la educación obligatoria, y demostrar la incoherencia existente entre ambas, se ha propuesto una unificación de términos que permita conectar de manera clara el marco de la evaluación de las enseñanzas universitarias y no universitarias en relación a la FIP. Además, el intento de definición ha ido acompañado de una ejemplificación que ha intentado presentar los matices que diferencian a los distintos términos y conceptos implicados.

Somos conscientes de las limitaciones de la propuesta al presentar una única experiencia, sobre todo, en relación a la necesidad de los docentes de aceptar determinados cambios en su día a día. Sin embargo, sin duda, servirá de punto de partida para la reflexión de uno de los problemas que menos se tratan en la docencia universitaria: la incoherencia entre lo que enseñamos y es necesario en la vida profesional para la que ¿preparamos?

\section{Referencias bibliográficas}

Alonso-Cortés, M. D., Pérez-Pueyo, A., Diez-Fernández, M. A., Domínguez-Fernández, R., García-González, M.E., González-Alonso, M. I., Gutiérrez-García, C., y Fernández-Fernández, R., (2015). Escala de valoración para el prácticum del máster en formación del profesorado de educación secundaria por parte de los tutores de los centros. En M. Raposo-Rivas, P. César Muñoz, Mª A. Zabalza, Ma E. Martínez-Figueira, y A. Pérez (coords.). Educar para evaluar experiencias de prácticum (pp. 433-436). Vigo: Andavira Editora, S.A.

Algozzine, B., Beattie, J., Bray, M., Flowers, C., Gretes, J., Howley, L., Ganesh, M., \& Spooner, F. (2004). Student evaluation of college teaching: a practice in search of principles. Collegeteaching, 52(4), 134-141.

Álvarez, J.M. (2003). La evaluación a examen. Madrid: Miño y Dávila.

Álvarez, J. M. (2005). Evaluar para conocer, examinar para excluir. Madrid: Morata. 
Álvarez, J.M. (2009). La evaluación en la práctica del aula. Revista de Educación, 350, 351-374.

Arribas, J. M., Carabias, D., y Monreal, I. (2010). La docencia universitaria en la formación inicial del profesorado. El caso de la escuela de magisterio de Segovia. REIFOP, 13(3), 27-35.

Bain, K. (2005). Lo que hacen los mejores profesores universitarios. Valencia: Universidad de Valencia.

Biggs, J. B. (1999). Teaching for Quality Learning at University.Buckingham: Open University Press.

Biggs, J. (2005). Calidad del aprendizaje universitario. Madrid: Narcea.

Boud, D. (Ed). (1995). Enhancing learning through self-assessment. London: Kogan Page.

Boud, D., \& Falchikov, N. (Eds.). (2007). Rethinking Assessment in Higher Education. Learning for the long term. London: Routledge.

Brown, S., \& Glasner, A. (Eds.). (1999). Assessment Matters in Higher Education. Buckingham: Open UniversityPress.

Brown, S., \& Pickforf, R. (2013). Evaluación de habilidades y competencias en educación superior. Madrid: Narcea.

Buscà, F., Pintor:, Martínez, L., y Peire, T. (2010). Sistemas y procedimientos de evaluación formativa en docencia universitaria: resultados de 34 casos aplicados durante el curso académico 2007-2008. Estudios sobre Educación 18, 255 - 276.

Camacho, H. M., y Padrón, M. (2006). Malestar docente en la formación inicial del profesorado: percepción del alumnado. Revista Interuniversitaria de Formación del Profesorado, 20(2), 209-230.

Conde, A., y Pozuelo, F. (2007). Las plantillas de evaluación (rúbrica) como instrumento para la evaluación. Un estudio de caso en el marco de la reforma de la enseñanza universitaria en el EEES. Investigación en la Escuela, 63, 77-90.

Coraggio, J. L., y Torres, R. M. (1997). La educación según el Banco Mundial. Un análisis de sus propuestas y métodos. Buenos Aires: Miño y Dávila. 
Corredor, J. y Romero, C. A. (2008). Planeación, organización y expresión de un tipo de discurso oral: la exposición. Consideraciones, sugerencias y recomendaciones. Cuadernos de Lingüística Hispánica, 12, 57-76.

Dochy, F., Segers,M., \& Dierick, S. (2002). Nuevas vías de aprendizaje y enseñanza y sus consecuencias: una era de evaluación. Red Estatal de Docencia Universitaria, 2(2), 13-30

Emery, C. R., Kramer, T. R., \& Tian, R. G. (2003). Return to academic standards: a critique of student evaluations of teaching effectiveness. Quality Assurance in Education, 11(1), 37-46.

Escudero, T., Pino, J. L., y Rodríguez, C. (2010). Evaluación del profesorado universitario para incentivos individuales: Revisión metaevaluativa. Revista de Educación, 351, 513-537.

Estatutos de la Universidad de León. Acuerdo 243/2003, de 23 de octubre, de la Junta de Castilla y León, por el que se aprueba el Estatuto de la Universidad de León (B.O.C. y L. de 29 de octubre)

Fernández-Pérez, M. (1989). Así enseña nuestra universidad. Salamanca: Hispagraphis. Fernández-Balboa, J.M. (2005). La auto-evaluación como práctica promotora de la democracia y la dignidad. En J.M. Fernández-Balboa y A. Sicilia (Eds.) La otra cara de la enseñanza. La Educación Física desde una perspectiva crítica (pp. 127-158). Barcelona: Inde.

González, L. (2004). La comprensión y producción de la exposición oral como técnica didáctica. Zona próxima: revista del Instituto de Estudios, 5, 86-111.

Gullickson, A. (2007). The Joint Committe on Standars for Educational Evaluation. Bilbao: Mensajero.

Hafner, J.C. \& Hafner:M. (2003).Quantitative analysis of the rubric as an assessment tool: an empirical study of student peer-group rating. International Journal of Science Education, 25 (12), 1509-1528. 
Hamodi, C., López-Pastor, V. M., y López-Pastor, A. T. (2015). Medios, técnicas e instrumentos de evaluación formativa y compartida del aprendizaje en educación superior. Perfiles Educativos, 147(27), 146-171.

Ibarra, M. S., y Rodríguez, G. (2010). Aproximación al discurso dominante sobre la evaluación del aprendizaje en la universidad. Revista de Educación, 351, 385407.

Ibarra, M. S., Rodríguez, G., y Gómez, M. G. (2012). La evaluación entre iguales: beneficios y estrategias para su práctica en la universidad. Revista de Educación, $359,206-231$.

Ibarra, M.S., Rodríguez, G., Cotrina, M., García, M.C., y Del Barco, L. (2006). Proyecto SISTEVAL: Recursos para el establecimiento de un sistema de evaluación del aprendizaje universitario basado en criterios, normas y procedimientos públicos y coherentes. Ministerio de Educación y Ciencia y la Universidad de Cádiz. Cádiz: Universidad de Cádiz.

Knight: (2005). Calidad del aprendizaje universitario. Narcea: Madrid.

Ley Orgánica 1/1990, de 3 de octubre, de Ordenación General del Sistema Educativo. Madrid. (B.O.E. de 4 de octubre).

Ley Orgánica 6/2001, de 21 de diciembre, de Universidades (B.O.E. de 24 de diciembre).

Ley Orgánica 2/2006, de 3 de mayo, de Educación (B.O.E., 4 de Mayo).

Ley Orgánica 4/2007, de 12 de abril, por la que se modifica la Ley Orgánica 6/2001, de 21 de diciembre, de Universidades (B.O.E. de 13 de abril).

Ley Orgánica 8/2013, de 9 de diciembre, para la mejora de la calidad educativa (B.O.E., 10 de Diciembre).

López-Pastor, V. M. (2006). El papel de la Evaluación Formativa en el proceso de Convergencia hacia el EEES. Análisis del estado de la cuestión y presentación de un sistema de intervención. Revista Interuniversitaria de Formación del Profesorado,57, 93-120. 
López-Pastor, V. M. (2008). Implementing a Formative and Shared Assessment System in Higher Education Teaching. European Journal of Teacher Education, 31(3), 293-311.

López-Pastor, V. M. (Coord.). (2009). La Evaluación Formativa y Compartida en Docencia Universitaria: propuestas, técnicas, instrumentos y experiencias. Madrid: Narcea.

Marcelo, C., y Vaillant, D. (2009). Desarrollo profesional docente: ¿Cómo se aprende a enseñar? Madrid: Narcea.

Manrique, J. C., López-Pastor, V. M., Monjas, R., Gea, J. M., y Barba, J. (2010). Investigación y cambio social: un proyecto de $\mathrm{I}+\mathrm{D}+\mathrm{I}$ para transformar el programa de deporte escolar de toda la ciudad. Actas $V$ Congreso Internacional de Educación Física. Barcelona: Universidad de Barcelona.

M.E.C. (1992). Materiales para la Reforma. Proyecto curricular. Primaria. Madrid: Servicio de publicaciones.

M.E.C. (1996). Programación. Secundaria. Madrid: Servicio de publicaciones.

Menéndez, J. L. (2013). Rúbricas para la evaluación de proyectos de AprendizajeServicio en los estudios universitarios de las Artes. Observar, 7, 5-24.

Orden ECI/2572/2007, de 4 de septiembre, sobre evaluación en Educación secundaria obligatoria (B.O.E., 4 de Septiembre).

Orden EDU/1952/2007, de 29 de noviembre, por la que se regula la evaluación en educación secundaria obligatoria en la Comunidad de Castilla y León (B.O.C.y.L., de 7 de Diciembre).

Orden EDU/888/2009, de 20 de abril, por la que se regula el procedimiento para garantizar el derecho del alumnado que cursa enseñanzas de educación secundaria obligatoria y de bachillerato, en centros docentes de la Comunidad de Castilla y León, a que su dedicación, esfuerzo y rendimiento sean valorados y reconocidos con objetividad (B.O.C.y.L, 27 de abril).

Orden ECD/65/2015, de 21 de enero, por la que se describen las relaciones entre las competencias, los contenidos y los criterios de evaluación de la educación 
primaria, la educación secundaria obligatoria y el bachillerato (B.O.E., 29 de Enero).

Orden EDU/362/2015, de 4 de mayo, por la que se establece el currículo y se regula la implantación, evaluación y desarrollo de la educación secundaria obligatoria en la Comunidad de Castilla y León (B.O.C.y.L, 8 de Mayo).

Palacios, A., y López-Pastor, V. M. (2013). Haz lo que yo digo pero no lo que yo hago: sistemas de evaluación del alumnado en la formación inicial del profesorado. Revista de Educación, 361, 279-305. DOI: 10.4438/1988-592X-RE-2011-361143

Pérez-Pueyo, A. (2010). El Estilo Actitudinal. Propuesta metodológica para desarrollar unidades didácticas en educación física. Madrid: Editorial CEP S.L.

Pérez-Pueyo, A. (2015a). El Estilo Actitudinal en Educación Física: Evolución en los últimos 20 años. Retos. Nuevas tendencias en Educación Física, Deporte y Recreación, 29, 207-215

Pérez-Pueyo, A. (2015b). Escala de valoración para la evaluación triádica de exposiciones orales. En N. González, I. Salcines y E. García (coord.) Tendencias emergentes en evaluación formativa y compartida en docencia. El papel de las nuevas tecnologías II, pp. 1257-1288. Santander. Editorial de la Universidad de Cantabria.

Pérez-Pueyo, A., Hortigüela, D., y Hernando, A. (2014). La coevaluación intragrupal y el reparto de notas bajo un proceso de evaluación formativa. En P. Membiela, N. Casado y M I: Cebreiros (coords.) Experiencias e innovación docente en el contexto actual de la docencia universitaria (pp. 285-289) Orense: Edición Editora.

Pérez-Pueyo, A., Diez-Fernández, M. A., Domínguez-Fernández, R., García-González, M.E., Fernández-Fernández, R., González-Alonso, M. I., y Alonso-Cortés, M. D. (2014). Proceso de elaboración de una rúbrica para la evaluación del Prácticum del Máster de E. Secundaria por parte de los tutores de los centros. En A. Calvo-Salvador, C. Rodríguez-Hoyos y I. Haya Salmón (coords.). Investigar para acompañar el cambio educativo y social. El papel de la universidad (pp. 
967-977). Santander: AUFOP Universidad de Cantabria. Recuperado de: https://metodologiainclusiva.files.wordpress.com/2014/12/actascongreso-aufop2014-santander-v3.pdf.

Pérez-Pueyo, Á., Julián, J. A., y López-Pastor, V. M. (2009). Evaluación formativa y compartida en el Espacio Europeo de Educación Superior (EEES). En V. M. López-Pastor (coord.), Evaluación formativa y compartida en educación superior(pp. 19-43). Madrid: Narcea.

Pérez-Pueyo, A., Tabernero, B., López-Pastor, V. M., Ureña, N., Ruiz, E., Caplloch, M,... Castejón, F. J. (2008). Evaluación formativa y compartida en la docencia universitaria y el Espacio Europeo de Educación Superior: cuestiones clave para su puesta en práctica. Revista de educación, 347, 435-451

Pérez-Pueyo, A. (2015). El estilo actitudinal en educación física. Evolución en los últimos 20 años.

Perrenoud: (2004). Diez nuevas competencias para enseñar. Barcelona: Graó.

Pontes, A., Serrano, R., y Poyato, F.J. (2013). Concepciones y motivaciones sobre el desarrollo profesional docente en la formación inicial del profesorado de enseñanza secundaria. Revista Eureka sobre Enseñanza y Divulgación de las Ciencias, 10 ( $\mathrm{N}^{\mathrm{o}}$ Extra), pp. 533-531

Pontes, A., y Poyato, F.J. (2014). El enfoque reflexivo en la formación inicial del profesorado de secundaria: Motivaciones por la docencia. Cuadernos de Pedagogía, 445 , pp. 34-37

Pontes, A., Poyato, F. J., y Oliva, J. M. (2014). Actividades para reflexionar sobre los procesos de aprendizaje en la formación inicial del profesorado de enseñanza secundaria. International Journal for 21st Century Education, 1, 47-56.

Real Decreto 83/1996, de 26 de enero, por el que se aprueba el Reglamento Orgánico de los Institutos de Educación Secundaria (B.O.E., 21 de Febrero).

Real Decreto 1044/2003, de 1 de agosto, por el que se establece el procedimiento para la expedición por las universidades del Suplemento Europeo al Título (BOE 11 de septiembre). 
Real Decreto 1125/2003, de 5 de septiembre, por el que se establece el sistema europeo de créditos y el sistema de calificaciones en las titulaciones universitarias de carácter oficial y validez en todo el territorio nacional (BOE 18 de septiembre).

Real Decreto 55/2005, de 21 de enero, por el que se establece la estructura de las enseñanzas universitarias y se regulan los estudios universitarios oficiales de Grado (B.O.E. de 25 de enero).

Real Decreto 56/2005, de 21 de enero, por el que se regulan los estudios universitarios oficiales de Posgrado (B.O.E. 25 de Enero).

Real Decreto 276/2007, de 23 de febrero, por el que se aprueba el Reglamento de ingreso, accesos y adquisición de nuevas especialidades en los cuerpos docentes a que se refiere la Ley Orgánica 2/2006, de 3 de mayo, de Educación, y se regula el régimen transitorio de ingreso a que se refiere la disposición transitoria decimoséptima de la citada ley (B.O.E., 2 de Marzo).

Resolución de 5 de marzo de 1992 de la Secretaría de Estado de Educación, que regula la elaboración de proyectos curriculares para la Educación Secundaria Obligatoria y se establecen orientaciones para la distribución de objetivos, contenidos y criterios de evaluación para cada uno de los ciclos (B.O.E., 25 de marzo).

Rodríguez, G., y Ibarra, M. S. (2011). e-Evaluación orientada al e-aprendizaje estratégico en educación superior. Madrid: Narcea.

Rodríguez-Gómez, G. y Ibarra-Sáiz, M.S. (2015). Assessment as Learning and Empowerment: Beyond Sustainable Learning in Higher Education. In M. PerisOrtiz, y J. M. Merigó (Eds.), Sustainable learning in higher education, innovation, technology, and knowledge management. (pp. 1-20). London: Springer-Verlag. doi:10.1007/978-3-319-10804-9_1

Rodríguez-Gómez, G., Ibarra-Sáiz, M. S. y Gómez-Ruiz, M. A. (2011). eAutoevaluación en la universidad. Un reto para profesores y estudiantes. Revista de Educación, 356, 401-430. 
Salinas, B., y Costilla, C. (2007). Evaluación de los estudiantes en la educación superior. Apuntes de buenas práctica. Valencia: Servicio de Formación Permanente. Universidad de Valencia.

Santos, M.; Martínez, L.F., y López-Pastor, VM. (coords.) (2009). La Innovación docente en el EEES. Almería: Editorial Universidad de Almería.

Silva, I. y López-Pastor, V. M. (2015). ¿Cómo vive el alumnado la evaluación en formación inicial del profesorado?@TIC, Revista de innovación Educativa, 14, 1-11 DOI: 10.7203/attic.14.4171

Tejedor, F. J. (Dir.). (1998). Las estrategias utilizadas por los profesores universitarios para la evaluación del aprendizaje de los alumnos. Madrid: CIDE.

Torres, J. J., y Perera, V. H (2010). La rúbrica como instrumento pedagógico para la tutorización y evaluación de los aprendizajes en el foro online en Educación Superior. Revista de Medios y Educación, 36, 141-149. Recuperado de http://www.sav.us.es/pixelbit/pixelbit/articulos/n36/11.html 